\title{
Инварианты пространственных разбиений в минеральной и биологической природе
}

Войтеховский Ю.Л. ${ }^{1,2}$, Чукаева М.А. ${ }^{2}$, Степенщиков Д.Г. ${ }^{1}$

${ }^{1}$ Геологический институт ФИЦ КНЦ РАН, Anamumbl,woyt@geoksc.apatity.ru

${ }^{2}$ Санкт-Петербургский горный университет, Санкт-Петербург

Аннотация. В статье показано, что в морфологии абстрактных геометрических (выпуклые полиэдры), минеральных (системы трещин в различных материалах, кристаллы, фуллерены) и биологических (икосаэдрические Viruses, кораллы Favites sp., одуванчики Taraxacum officinale., колючие рыбы Diodon holocanthus.) объектов закономерно присутствуют инварианты разбиений поверхностей, обусловленные геометрией $2 \mathrm{D}$ и 3D евклидовых пространств, а не спецификой онтогенеза. При этом фундаментальную роль играет теорема Эйлера о планарных графах. Специфику онтогенеза следует искать в отклонениях от пространственных инвариантов.

Ключевые слова: полигональное разбиение поверхности, разбиение по Вороному-Дирихле, триангуляция Делоне, инвариант, минеральные и биологические объекты.

\section{Invariants of spatial partitions in mineral and biological nature}

Voytekhovsky Y.L. ${ }^{1,2}$, Chukaeva M.A. ${ }^{2}$, Stepenshchikov D.G. ${ }^{1}$

${ }^{1}$ Geological Institute of FRC KSC RAS, Apatity,woyt@geoksc.apatity.ru

${ }^{2}$ Saint Petersburg Mining University, Saint Petersburg

Abstract. The article shows that in the morphology of abstract geometric (convex polyhedra), mineral (systems of cracks in various materials, crystals, fullerenes) and biological (icosahedral Viruses, corals Favites sp., dandelions Taraxacum officinale, spiny fish Diodon holocanthus) objects there are invariants of surface tilings owing to the geometry of 2D and 3D Euclidean spaces, and not to the ontogenetic specifics. In this case, Euler's theorem on planar graphs plays a fundamental role. The ontogenetic specifics should be sought in deviations from spatial invariants.

Key words: polygonal tiling of a surface, Voronoy-Dirichlet subdivision, Delaunay triangulation, invariant, mineral and biological objects.

Пандемия COVID-19 заставила пристально рассмотреть структуры вирусов - казалось бы, примитивных образований на границе живого и косного. Их эффективность бесспорна, коль скоро ставит под сомнение существование нашего биологического вида. Их икосаэдрические капсиды белковые оболочки, покрывающие молекулы ДНК / РНК - столь совершенны, что кажутся уникальными для нашего мира. Цель статьи - показать, что даже они суть частные случаи общей закономер-
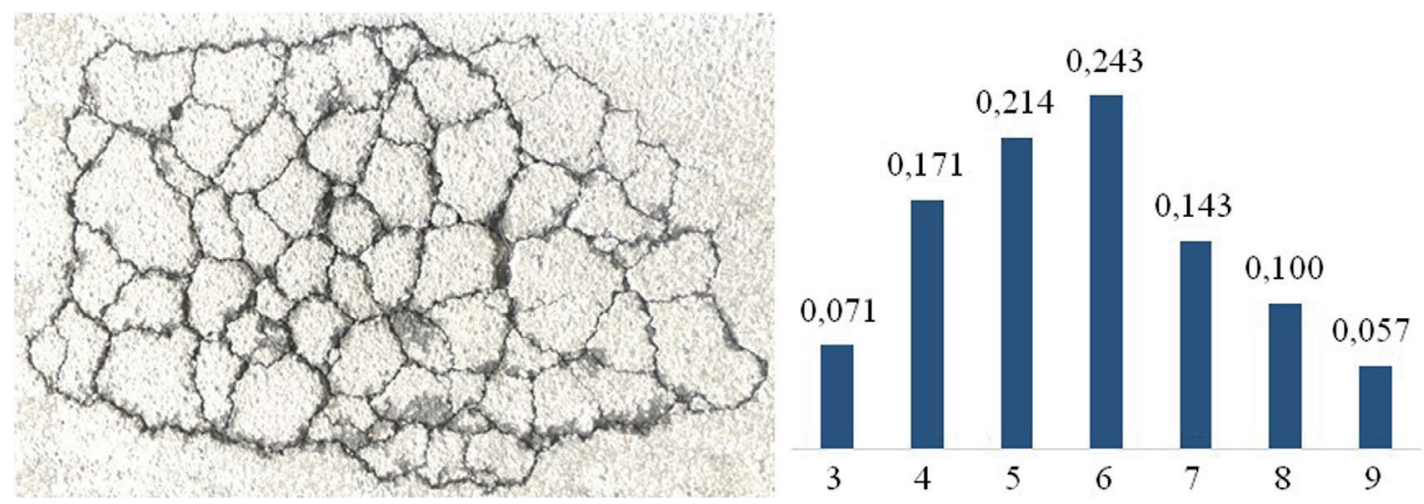

Рис. 1. Система трещин на асфальте - планарный граф. Здесь и далее на гистограммах по вертикальной оси частота клеток с разной координацией.

Fig. 1. A system of cracks on asphalt - a planar graph. Hereinafter on the histograms, along the vertical axis - the frequency of cells with different coordination. 
ности, присущей полигональным разбиениям поверхностей в 2D и 3D евклидовых пространствах. Она обобщает предыдущие публикации авторов, посвященные отдельным объектам.

Для любого плоского графа выполняется теорема Эйлера: $\mathrm{f}-\mathrm{e}+\mathrm{v}=2$, где $\mathrm{f}-$ число клеток, $\mathrm{e}-$ peбер, $\mathrm{v}-$ вершин. Если из каждой вершины выходят ровно три ребра, то $3 \mathrm{v}=2 \mathrm{e}$ и e $=3 \mathrm{f}-6$. Тогда средняя координация клетки равна: $\mathrm{c}=2 \mathrm{e} / \mathrm{f}=6-12 / \mathrm{f} \rightarrow 6$ при $\mathrm{f} \rightarrow \infty$. Для графа на рис. $1: \mathrm{f}=71$, $\mathrm{e}=225, \mathrm{v}=156$. Так как координация клетки варьирует, охарактеризуем статистику стандартным образом: $\mathrm{Mo}=6, \mathrm{c}=5.74, \sigma=1.59, \mathrm{As}=0.23, \mathrm{Ex}=-0.82$. Более широкий круг аналогичных природных объектов приведен в статье (Войтеховский, 2018). Равенство с $=6$ без асимптотики, в стиле кристаллографической правильности, известно нам в единственном природном объекте - пчелиных сотах.

Каждый плоский граф может быть расправлен в выпуклый полиэдр. То есть, с $\rightarrow 6$-инвариант для простых (в каждой вершине сходятся три грани) плоских графов и выпуклых полиэдров. Для последних (Войтеховский, Степенщиков, 2008 a, б) асимптотику с $\rightarrow 6$ можно проследить на примерах: тетраэдр ( $\mathrm{f}=4, \mathrm{c}=3)$, тригональная призма $(5,3.6)$, куб $(6,4)$, комбинация двух тетраэдров $(8,4.5)$, куб + тетраэдр $(10,4.8)$, пентагондодекаэдр $(12,5)$, куб + октаэдр $(14, \mathbf{5 . 1 4})$, куб + октаэдр + ромбододекаэдр $(26,5.54) \ldots$ Сквозь тенденцию проступает важный инвариант нашего мира, схваченный теоремой Эйлера.

Полигональное разбиение слабо искривленной поверхности не должно отличаться от плоского графа (иначе говоря, слабо искривленная поверхность гомеоморфна плоскости). В качестве примера авторами изучены 3 образца современного коралла Favites sp. В них кораллиты, нарастая на субстрат и тесня друг друга (конкурируя за пространство, как и в зоне геометрического отбора параллельно-шестоватых минеральных агрегатов), образуют полигональные разбиения условных аппроксимирующих поверхностей (рис. 2). Средние характеристики разбиений: $\mathrm{Mo}=6, \mathrm{c}=5.98$; $\sigma=0.97$, As $=-0.01, \mathrm{Ex}=-0.50$.
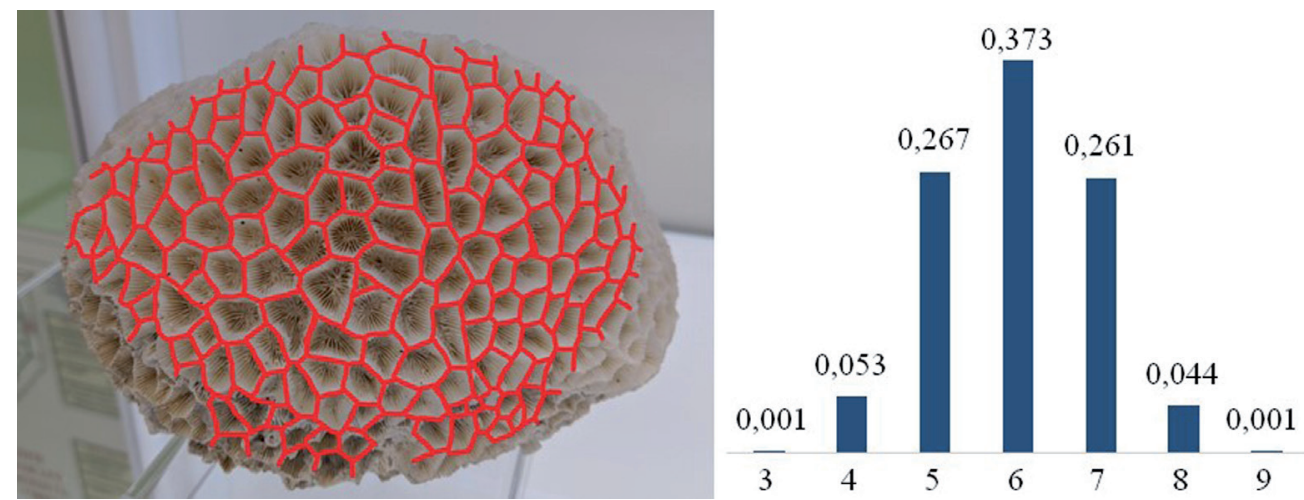

Рис. 2. Коралл Favites sp. Fig. 2. Coral Favites sp.

Гораздо более изогнутую поверхность предоставляет более высоко стоящий в иерархии природы обыкновенный одуванчик Taraxacum officinale. Отпечатки папиллусов, теснясь и образуя выпуклые перегородки, дают замечательное разбиение поверхности соцветия (рис. 3). Для одного образца получены характеристики разбиения: $\mathrm{Mo}=6, \mathrm{c}=5.97 ; \sigma=0.66, \mathrm{As}=0.03, \mathrm{Ex}=-0.68$.

Еще более изогнутую, квази-сферическую поверхность образует в возбужденном состоянии колючая рыба Diodon holocanthus (рис. 4). Принимая основания игл за точки и используя кристаллографическую технику триангуляций Делоне и дуальных построений по Вороному-Дирихле, авторы получили полигональные разбиения поверхностей для 8 образцов. Средние характеристики разбиений: $\mathrm{Mo}=6, \mathrm{c}=5.97 ; \sigma=0.58, \mathrm{As}=0.01, \mathrm{Ex}=-0.17$.

Фуллерены стали широко известны после синтеза стабильной молекулы $\mathrm{C}_{60}$ (рис. 5), положившей начало новому классу суперароматических соединений (Kroto et al., 1985), и присуждения в 1996 г. Х. Крото, Р. Керлу и Р. Смолли Нобелевской премии по химии. Но заметим, что еще в начале 

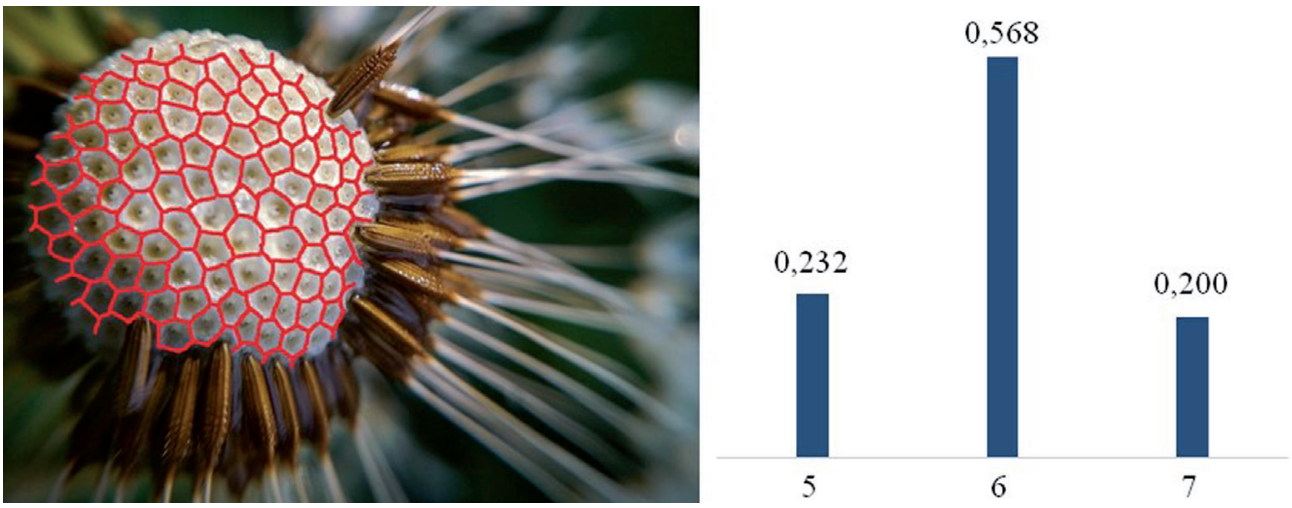

Рис. 3. Одуванчик Taraxacum officinale. Fig. 3. Dandelion Taraxacum officinale.

XX века те же ажурные структуры в скелетах Radiolaria увидел и зарисовал Э. Геккель (1902), затем их комбинаторную геометрию изучал Д’Арси У. Томпсон (Thompson, 1917), наконец, их физическую целесообразность (минимальный расход материала для охвата максимального объема при достаточной прочности конструкции) расчетом подтвердил Д.Д. Мордухай-Болтовской (1936). Позднее их распознали в пыльце растений, ценобиях зеленых водорослей Volvocacea и других биологических объектах.
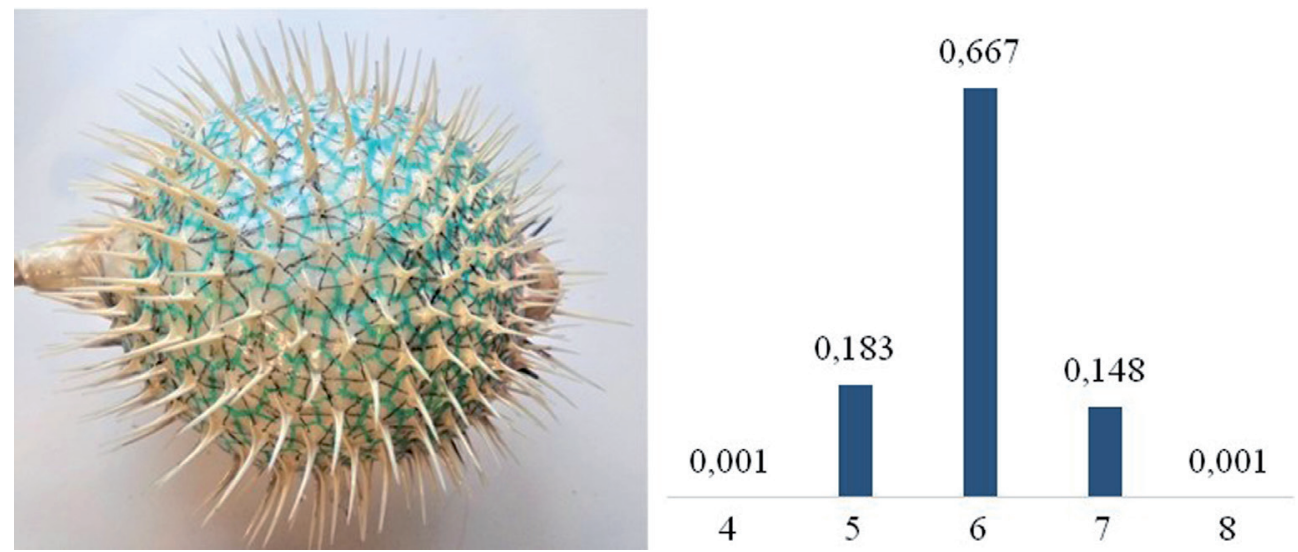

Рис. 4. Колючая рыба Diodon holocanthus. Fig. 4. Spiny fish Diodon holocanthus.

Но для этого пришлось расширить определение фуллерена с уникального икосаэдрического $\mathrm{C}_{60}$ (в нобелевском спектре был ешё явный пик $\mathrm{C}_{70}$ ) до любого выпуклого простого полиэдра, на котором разрешены лишь пентагоны и гексагоны. Их замечательным свойством оказалось то, что пентагонов всегда 12, гексагонов - любое число от 0 (платонов додекаэдр) до $\infty$, кроме 1 (рис. 5).
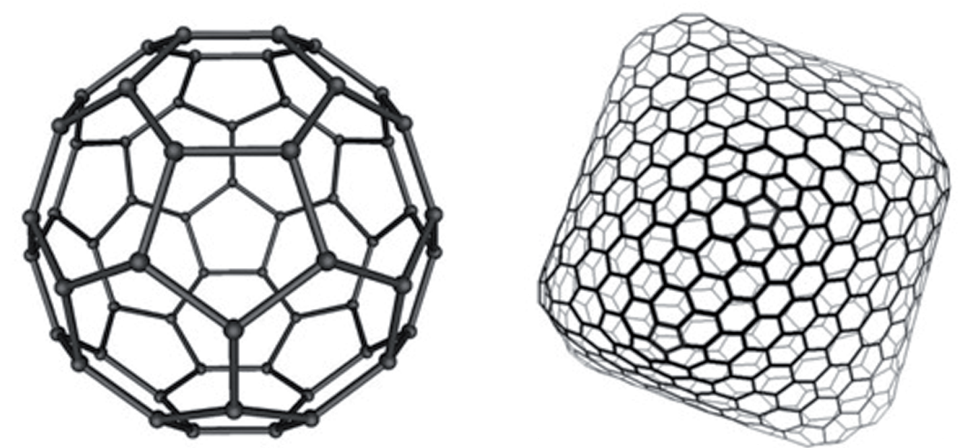

Рис. 5. Фуллерен $\mathrm{C}_{60}$ (слева) и $\mathrm{C}_{696}$ (справа). Fig. 5. Fullerene $\mathrm{C}_{60}$ (left) and $\mathrm{C}_{696}$ (right). 

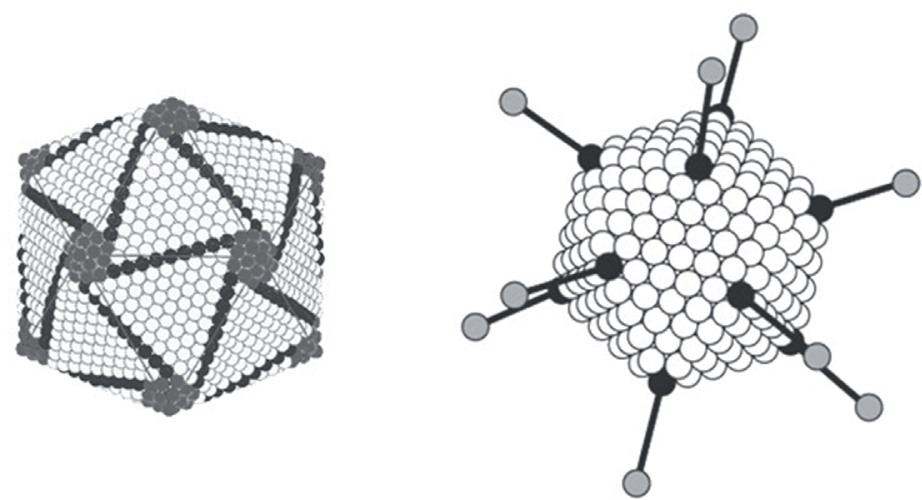

Рис. 6. Капсиды вирусов с симметрией Y (слева, иридовирус) и $\mathrm{Y}_{\mathrm{h}}$ (справа, аденовирус).

Fig. 6. Capsids of the viruses with $\mathrm{Y}$ (left, Iridoviridae) and $\mathrm{Y}_{\mathrm{h}}$ (right, Adenoviridae) symmetry.

У всякого простого полиэдра $\mathrm{f}=(\mathrm{v}+4) / 2$. Поэтому формула для средней координации клетки (грани) преобразуется к виду: $\mathrm{c}=6-24 /(\mathrm{v}+4)$. Для $\mathrm{C}_{60}$ получим $\mathrm{c}=5.625$, для $\mathrm{C}_{696}-5.966$. Она близка к 6 для еще более крупных фуллеренов (Степенщиков, 2016). Обзор их точечных групп симметрии в диапазоне $\mathrm{C}_{20}-\mathrm{C}_{100}$ дан в каталогах (Войтеховский, Степенщиков, 2002, 2003).

Икосаэдрические вирусы, в том числе COVID-19, копируют структуру икосаэдра и дуального к нему додекаэдра. В первом приближении их капсиды имеют симметрии Ү (без плоскостей симметрии) и $\mathrm{Y}_{\mathrm{h}}$ (с плоскостями симметрии, рис. 6). Все отношения, найденные первыми исследователями (Crick, Watson, 1956; Caspar, Klug, 1962), переводятся на язык геометрии фуллеренов. Основные структурные единицы - пентоны (всегда 12) и гексоны (от 0 у бактериофага $\varphi$ X174 до пока не установленного предела в мегавирусах, кроме 1). Очевидно, здесь имеет место уже известная асимптотика с $\rightarrow 6$. В статье (Войтеховский, 2020 а) дано представление многообразия икосаэдрических вирусов в форме сплетения их гомологических серий.

Известно, что икосаэдр и додекаэдр противоречат классической кристаллографии из-за наличия в них осей симметрии 5-го порядка. Между тем, Е.С. Федоров (1915) и В.В. Доливо-
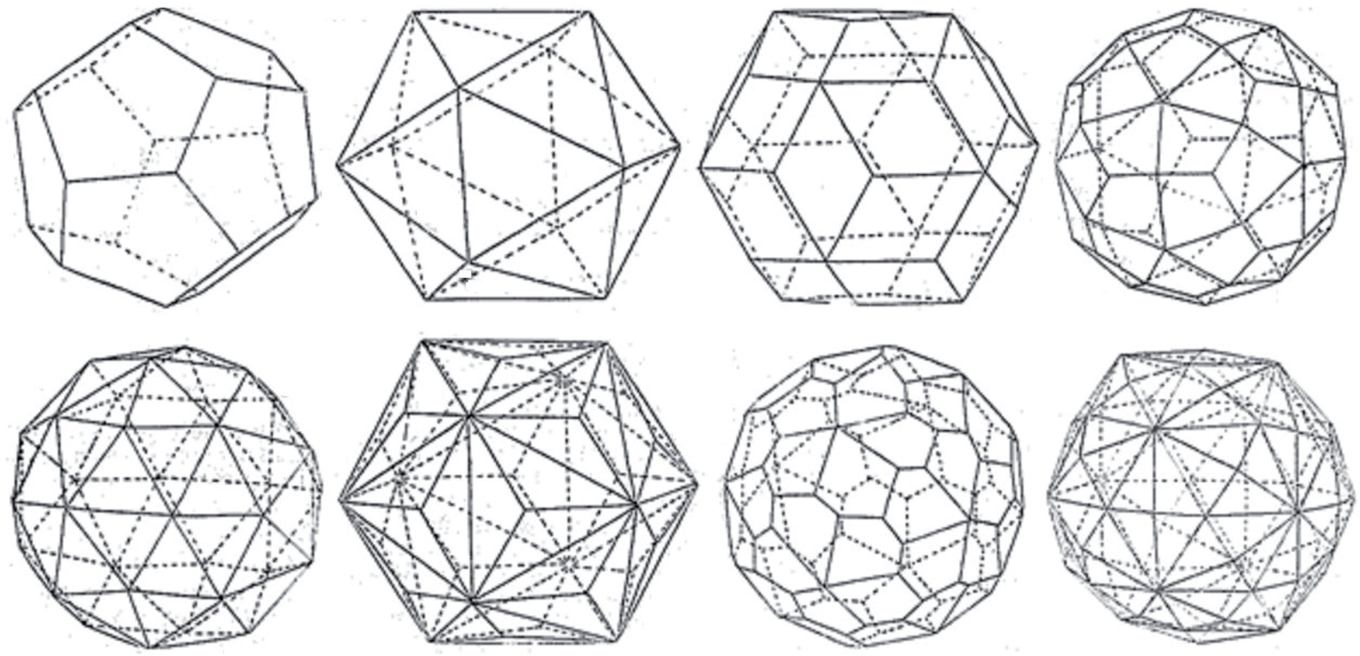

Рис. 7. Простые формы с точечными группами симметрии $\mathrm{Y}_{\text {и }} \mathrm{Y}_{\mathrm{h}}$, в скобках - число граней. Вверху: додекаэдр (12), икосаэдр (20), триаконтаэдр (30), тетрагонтриикосаэдр (60). Внизу: тригонпентадодекаэдр (60), тригонтриикосаэдр (60), пентагонтриикосаэдр (60, общая форма в Y), гексаикосаэдр (120, общая форма в $\mathrm{Y}_{\mathrm{h}}$ ).

Fig. 7. Simple forms with $\mathrm{Y}_{\mathrm{h}}$ and $\mathrm{Y}$ point symmetry groups, the number of faces are in brackets. Top: dodecahedron (12), icosahedron (20), triacontahedron (30), tetragontriicosahedron (60). Bottom: trigonpentadodecahedron (60), trigontriicosahedron (60), pentagontriicosahedron (60, general form in $\mathrm{Y})$, hexaicosahedron (120, general form in $\mathrm{Y}_{\mathrm{h}}$ ). 
Добровольский (1924) всегда рассматривали их в кристаллографических работах в составе додекаэдро-икосаэдрической системы. Признание квази-кристаллов (Shechtman et al., 1984) полноправными кристаллами, активное изучение икосаэдрических вирусов и фуллеренов методами кристаллографии - все это побуждает нас к признанию икосаэдра и додекаэдра в составе додекаэдро-икосаэдрической сингонии (Войтеховский, 2020) с аксиальным I и планаксиальным $\mathrm{I}_{h}$ видами симметрии (рис. 7). В целом рассмотренные примеры приводят нас к выводу, что кроме материально-энергетического единства минеральных и биологических объектов есть более глубокие инварианты, обусловленные их вложением в 2D и 3D евклидовы пространства. В этом смысле они кристаллографичны (Галиулин, 2002). В нашем случае это число 6, проявляющееся как мода и асимптотически - как среднее в статистиках полигональных разбиений самых разных поверхностей. В чем же проявляется онтогенез? По-видимому, в отклонениях от инварианта (идеала), выражаемых в дисперсии, асимметрии, эксцессе... Заметим, что именно такой логике следует учение об онтогении минералов (Григорьев, 1961).

\section{Литература}

1. Войтеховский Ю.Л. Типизация неправильных пространственных разбиений // Вестник ИГ Коми НЦ УрО РАН. 2018. № 8. С. 46-50. doi: 10.19110/2221-1381-2018-8-46-50.

2. Войтеховский Ю.Л. Из опыта преподавания. III. Кристаллография икосаэдрических вирусов // Вестник геонаук. 2020 а. № 4. C. 40-44. doi:10.19110/geov.2020.4.6.

3. Войтеховский Ю.Л. Додекаэдро-икосаэдрическая система // Зап. РМО. 2020 б. №6. С. 101-109. doi:10.31857/S0869605520060155.

4. Войтеховский Ю.Л., Степенщиков Д.Г. Фуллерены С20 - С60: каталог комбинаторных типов и точечных групп симметрии. Апатиты. Изд-во: ЗАО «К \& М». 2002. 55 с.

5. Войтеховский Ю.Л., Степенщиков Д.Г. Фуллерены С62 - С100: каталог комбинаторных типов и точечных групп симметрии. Апатиты. Изд-во: ЗАО «К \& M». 2003. 50 с.

6. Войтеховский Ю.Л., Степенщиков Д.Г. Комбинаторная кристалломорфология. Кн. IV. Выпуклые полиэдры. Т. І. 4- ... 12-эдры. Апатиты. Изд-во: КНЦ РАН. 2008 а. 833 с.

7. Войтеховский Ю.Л., Степенщиков Д.Г. Комбинаторная кристалломорфология. Кн. IV. Выпуклые полиэдры. Т. ІІ. Простые 13- ... 16-эдры. Апатиты. Изд-во: КНЦ РАН. 2008 б. 828 с.

8. Галиулин Р.В. Кристаллографическая картина мира // Успехи физ. наук. 2002. Т. 172. № 2. С. 229-233.

9. Геккель Э. Красота форм в природе. СПб Изд-во: Т-во «Просвещение». 1902. 120 с.

10. Григорьев Д.П. Онтогения минералов. Львов. Изд-во Львовского ун-та. 1961. 284 с.

11. Доливо-Добровольский В.В. Исследование додекаэдро-икосаэдрической системы // Зап. РМО. 1924. № 1. С. 169-181.

12. Мордухай-Болтовской Д.Д. Геометрия радиолярий // Уч. зап. Ростов-н / Д. гос. ун-та. 1936. № 8. С. 3-91.

13. Степенщиков Д.Г. Морфология и симметрия гигантских фуллеренов // Рос. нанотехно-логии. 2016. № 7-8. C. 47-50.

14. Федоров Е.С. Практикум по основным отделам кристаллографии. Петроград: Экон. типо-литография, 1915. $20 \mathrm{c}$.

15. Caspar D.L.D., Klug A. Physical principles in the construction of regular viruses // Cold Spring Harbor Symp. Quant. Biol. 1962. V. 27. P. 1-24.

16. Crick F.H.C., Watson J.D. Structure of small viruses // Nature. 1956. V. 177. P. 473-475. doi: 10.1038/177473a0.

17. Kroto H. W., Heath J. R., O’Brien S. C., Curl R. F., Smalley R. E. C60: Buckminsterfullerene // Nature. 1985. V. 318. P. 162-163. doi:10.1038/318162a0.

18. Shechtman D., Blech I., Gratias D., Cahn J. W. Metallic phase with long-range otientational order and no translational symmetry // Phys. Rev. Let. 1984. V. 53. N 20. P. 1951-1953. doi:10.1103/PhysRevLett.53.1951.

19. Thompson D’Arsy W. On Growth and Form. Cambridge: University Press, 1917. 